\title{
SATISFAÇÃO PROFISSIONAL DO ENFERMEIRO NO AMBIENTE DA UNIDADE DE TERAPIA INTENSIVA
}

\author{
PROFESSIONAL SATISFACTION OF NURSES IN THE \\ INTENSIVE CARE UNIT ENVIRONMENT
}

\section{SATISFACCIÓN PROFESIONAL DE LAS ENFERMERAS EN EL ENTORNO DE LA UNIDAD DE CUIDADOS INTENSIVOS}

\author{
Emilenny Lessa dos Santos ${ }^{1}$ \\ Cícera Eugênia Pereira da Silva ${ }^{2}$ \\ Janine Melo de Oliveira ${ }^{3}$ \\ Viviane Farias Barros ${ }^{4}$ \\ Cyndi Myrelle da Silva Barros Romão 5 \\ Josefa Jadiane dos Santos ${ }^{6}$ \\ Mariana Barbosa da Silva ${ }^{7}$
}

Como citar este artigo: Santos EL, Silva CEP, Oliveira JM, Barros VF, Romão CMSB, Santos JJ, et al. Satisfação profissional do enfermeiro no ambiente da Unidade de Terapia Intensiva. Rev baiana enferm. 2021;33:e42812.

Objetivo: analisar a concepção do enfermeiro acerca da satisfação profissional no ambiente da Unidade de Terapia Intensiva. Método: estudo descritivo de abordagem qualitativa, realizado em um hospital universitário do estado de Sergipe. A coleta de dados foi realizada em outubro de 2020, por meio de entrevistas semiestruturadas com enfermeiros do setor de Unidade de Terapia Intensiva geral, e os dados foram analisados mediante Análise de Conteúdo. Resultados: dos depoimentos emergiram as seguintes categorias: processo de trabalho do enfermeiro nas Unidades de Terapia Intensiva; fatores que interferem na satisfação profissional do enfermeiro no ambiente da Unidade de Terapia Intensiva; e a relação do enfermeiro com a satisfação profissional no ambiente de terapia intensiva durante a pandemia Covid-19. Considerações finais: na concepção dos enfermeiros da Unidade de Terapia Intensiva, a satisfação profissional é um aspecto importante no seu ambiente de trabalho e pode influenciar na prestação da assistência ofertada aos pacientes.

Descritores: Satisfação no Trabalho. Unidades de Terapia Intensiva. Enfermagem de Cuidados Críticos.

Objective: to analyze the nurse's conception of professional satisfaction in the Intensive Care Unit environment. Method: descriptive study of qualitative approach, carried out in a university hospital in the state of Sergipe. Data collection was performed in October 2020, through semi-structured interviews with nurses from the general Intensive Care Unit sector, and the data were analyzed through Content Analysis. Results: the following categories emerged from the statements: the work process of nurses in Intensive Care Units; factors that interfere in the professional satisfaction

\footnotetext{
Enfermeira. Especialista em Saúde do Adulto e do Idoso. Aracaju, Sergipe, Brasil. lessa.emilenny@outlook.com. http://orcid.org/0000-0002-2741 - I702 Enfermeira. Mestre em Enfermagem. Enfermeira do Hospital Universitário de Aracaju. Aracaju, Sergipe, Brasil. http://orcid.org/0000-0002-6480-2 I04.

Enfermeira. Mestre em Enfermagem. Docente da Universidade Federal de Alagoas e da Universidade Estadual de Ciências da Saúde de Alagoas. Maceió, Alagoas, Brasil. http://orcid.org/0000-0002-8816-2244

4 Enfermeira. Especialista em Envelhecimento e Saúde do Idoso. Enfermeira do Hospital Universitário de Aracaju. Aracaju, Sergipe, Brasil. http://orcid.org/0000-00025709-3354.

Enfermeira. Especialista em Infectologia. Enfermeira da Assessoria Técnica de Doenças Imunopreveníveis e Vacinação da Secretaria Estadual de Saúde de Alagoas. Maceió, Alagoas, Brasil. http://orcid.org/0000-0002-5134-0342.

6 Enfermeira. Especialista em Saúde do Adulto e do Idoso. Aracaju, Sergipe, Brasil. http://orcid.org/0000-000 I-6254-0449.

Enfermeira. Especialista em Saúde do Adulto e do Idoso. Enfermeira do Programa Nacional de Imunização da Secretaria Estadual de Saúde de Alagoas. Maceió, Alagoas, Brasil. http://orcid.org/0000-0002-5866-1552.
} 
of nurses in the Intensive Care Unit environment; and the relationship of nurses with professional satisfaction in the intensive care environment during the Covid-19 pandemic. Final considerations: in the conception of Intensive Care Unit nurses, professional satisfaction is an important aspect in their work environment and can influence the provision of care offered to patients.

Descriptors: Job Satisfaction. Intensive Care Units. Critical Care Nursing.

Objetivo: analizar la concepción de satisfacción profesional de la enfermera en el entorno de la Unidad de Cuidados Intensivos. Método: estudio descriptivo del enfoque cualitativo, realizado en un hospital universitario en el estado de Sergipe. La recogida de datos se realizó en octubre de 2020, a través de entrevistas semiestructuradas con enfermeras del sector general de la Unidad de Cuidados Intensivos, y los datos fueron analizados a través del Análisis de Contenido. Resultados: de las declaraciones, surgieron las siguientes categorías: el proceso de trabajo de las enfermeras en unidades de cuidados intensivos; factores que interfieren con la satisfacción profesional de las enfermeras en el entorno de la Unidad de Cuidados Intensivos; y la relación de enfermeras con satisfacción profesional en el entorno de Cuidados Intensivos durante la pandemia Covid-19. Consideraciones finales: en la concepción de las enfermeras de la Unidad de Cuidados Intensivos, la satisfacción profesional es un aspecto importante en su entorno de trabajo y puede influir en la prestación de atención ofrecida a los pacientes.

Descriptores: Satisfacción del Trabajo. Unidades de Cuidados Intensivos. Enfermería de Cuidados Críticos.

\section{Introdução}

Desde os primórdios da sociedade, a atividade laboral é ferramenta fundamental no contexto social em que vivemos, pois possibilita a existência das interações sociais e traz impacto nos aspectos físicos e emocionais na vida do indivíduo ${ }^{(1)}$.

No entanto, com a expansão do capitalismo e a globalização, o processo de trabalho se modificou. Houve um aumento da produtividade e competitividade no mercado de trabalho, crescendo, assim, o nível de exigência em relação à qualificação, ritmo e carga horária de trabalho, fatores que podem comprometer a saúde física, mental e profissional do trabalhador ${ }^{(2)}$.

Ademais, em relação ao trabalho do profissional enfermeiro, este é considerado complexo e tem como base norteadora o cuidar do ser humano, tornando o paciente o sujeito principal da sua assistência ${ }^{(3)}$. Assim, no processo de trabalho do enfermeiro, cada vez mais está presente a prestação de cuidados ao paciente crítico. Neste, engloba a obtenção da história clínica do paciente, realização de exame físico, planejamento da assistência, acompanhamento durante o transporte inter-hospitalar para realização de exames, execução de procedimentos inerentes à sua profissão, incluindo o manuseio da tecnologia, monitorização e avaliação dos pacientes, supervisão dos cuidados, bem como a responsabilidade por tarefas gerenciais ${ }^{(4)}$.

Nesse sentido, o enfermeiro que atua na Unidade de Terapia Intensiva (UTI) tem o seu exercício profissional respaldado pela Lei do Exercício Profissional no $\mathrm{n}^{\mathrm{0}}$ 7498/86, na qual o art.11, dispõe que "O enfermeiro exerce todas as atividades de enfermagem cabendo-lhe: 1) privativamente: planejamento, organização, coordenação, execução e avaliação dos serviços da assistência de enfermagem”"(5). Essa lei ressalta ainda que é atividade privativa do enfermeiro prestar cuidados de maior complexidade técnica, que exijam conhecimento científico específico e tomada de decisões ${ }^{(5)}$.

Dessa forma, o enfermeiro de UTI presta assistência ao paciente crítico com risco de morte iminente, o qual exige uma assistência ininterrupta, além de equipamentos e recursos humanos especializados. Diante da complexidade desse setor hospitalar, é essencial que o enfermeiro associe as habilidades técnicas com a tecnologia, dominando os princípios científicos em cada procedimento executado e, ao mesmo tempo, contribuindo com o trabalho em equipe, visando exercer uma assistência de qualidade e segura ${ }^{(3)}$.

Vale ressaltar que a UTI é considerada por muitos como um ambiente sombrio, exaustivo e 
sobrecarregado do hospital devido aos inúmeros procedimentos invasivos. Na UTI, o enfermeiro lida constantemente com a morte, com a rotina rígida e inflexível e a necessidade de manter os sentidos aguçados, em constante alerta, para agir de forma proativa em qualquer sinal de emergência. Dessa forma, a experiência de cuidar do paciente crítico acaba, muitas vezes, criando situações de estresse, problemas geradores de conflitos éticos e morais, exigindo do enfermeiro alta capacidade de decisão e autonomia ${ }^{(6)}$.

No tocante à complexidade da prestação da assistência ao paciente crítico, esta pode se tornar desafiadora até mesmo para os enfermeiros de UTI mais experientes, como foi evidenciado no cenário da pandemia da Covid-19. O vírus SARS-CoV-2, causador da Covid-19, desafiou a Organização Mundial de Saúde (OMS) e as estruturas organizacionais do sistema de saúde a rever o cuidado prestado aos pacientes críticos acometidos por essa patologia, a qual é altamente letal para grupos de risco, tem alto potencial de disseminação e ainda é desconhecida em alguns aspectos pela comunidade científica. Estes aspectos evidenciam, sobretudo, a responsabilidade por outras vidas, questão que se apresenta de forma inerente à atividade laboral do enfermeiro, caracterizando-o como um dos profissionais mais importantes na linha de frente de combate à pandemia ${ }^{(7-8)}$.

Nessa perspectiva, cabe salientar, ainda, que a satisfação profissional pode ser definida quando o trabalhador desempenha suas funções com entusiasmo, com sentimentos favoráveis em relação ao seu ambiente de trabalho, objetivando dar o melhor de si para prestar um cuidado de qualidade e seguro ao paciente, e, consequentemente, tornando o ambiente laboral mais harmonioso. Desse modo, torna-se compreensível que a satisfação profissional influencie na qualidade da assistência prestada e no modo como o profissional se sente em relação ao seu ambiente de trabalho ${ }^{(9)}$.

Nesse sentido, torna-se relevante a abordagem sobre o tema, visando melhor compreensão sobre o entendimento do enfermeiro em relação à satisfação profissional acerca do ambiente hospitalar no qual atua e as suas particularidades, além dos benefícios que isso pode acarretar no desenvolvimento de suas atividades perante a prestação da assistência ao paciente em cuidados intensivos.

Assim, o presente estudo procurou responder a seguinte questão norteadora: Qual a concepção do enfermeiro acerca da satisfação profissional no ambiente da Unidade de Terapia Intensiva? O objetivo desta pesquisa foi analisar a concepção do enfermeiro acerca da satisfação profissional no ambiente da Unidade de Terapia Intensiva.

\section{Método}

Trata-se de estudo qualitativo de cunho descritivo realizado em um hospital universitário do estado de Sergipe.

No período da coleta de dados, trabalhavam 15 enfermeiros no setor da UTI geral, dos quais 11 participaram do estudo e os demais não atenderam aos critérios de inclusão. Foram estabelecidos os seguintes critérios de inclusão na pesquisa: enfermeiros de ambos os sexos, sem restrição de idade, com tempo superior a dois anos de trabalho no setor. A escolha desses critérios deu-se por acreditar-se que, dessa forma, os sujeitos possuem vivência suficiente em sua prática profissional para fomentar o debate a respeito do tema. Os critérios de exclusão foram: enfermeiros impossibilitados de participar por motivo de saúde/doença, por se encontrarem de férias ou que, voluntariamente, expressassem, a qualquer momento, o desejo de interromper sua participação no estudo.

Os enfermeiros que atenderam a todos os critérios de inclusão foram convidados a participar do estudo e, posteriormente, a assinar o Termo de Consentimento Livre e Esclarecido (TCLE), consolidando a participação voluntária. Para assegurar o anonimato e sigilo das informações, para a identificação dos participantes, utilizou-se a letra "I", significando Intensivista, seguida da numeração de 1 a 11, de acordo com a ordem de realização das entrevistas.

A coleta de dados ocorreu no mês de outubro de 2020, com aplicação de entrevista 
semiestruturada cujo roteiro contou com 11 perguntas abertas. Para gravar os depoimentos coletados, foi utilizado um gravador. Posteriormente, as transcrições das entrevistas na íntegra foram feitas pela pesquisadora. Para analisar as falas dos entrevistados, optou-se por utilizar a técnica de análise de conteúdo temática proposta por Bardin, a qual contém as seguintes etapas: pré-análise (leitura flutuante); exploração do material (os dados são codificados em unidades de registro); tratamento dos resultados e interpretação (é feita a categorização e, posteriormente, o reagrupamento, em função de características comuns) ${ }^{(10)}$.

Em relação as etapas, conforme a técnica de análise de conteúdo, procedeu-se da seguinte forma: na primeira, houve o contato inicial do examinador com as falas dos entrevistados e foi feita uma leitura minuciosa de todo o material coletado; na segunda, foram selecionadas as falas que remetiam às unidades de registro que faziam ligação com um tema específico. Nesta etapa, selecionaram-se as unidades de registro.

Dando origem à primeira categoria, "processo de trabalho do enfermeiro de UTI", surgiram as unidades de registro de autonomia, a Sistematização da Assistência de Enfermagem (SAE), a tecnologia e o tipo de assistência prestada aos pacientes; já na categoria 2, "fatores que interferem na satisfação profissional do enfermeiro de UTI", as unidades de registro foram: remuneração, carga horária de trabalho e trabalho em equipe; e, por último, na categoria 3, "relação do enfermeiro de UTI com a satisfação profissional durante a pandemia Covid-19”, a unidade de registro foi satisfação profissional do enfermeiro no contexto da pandemia Covid-19.

Após perceber que esses discursos faziam conexões com temas específicos, efetuou-se a sua seleção para, posteriormente, agrupá-los na categoria com a qual faziam ligação. Nessa etapa, também foi escolhida a nomenclatura de cada categoria. Por fim, na terceira etapa, reavaliou-se a denominação das categorias e verificou-se a conformidade ou não dos agrupamentos feitos na etapa anterior. Em seguida, iniciou-se o tratamento dos resultados para realizar a interpretação baseada nos resultados encontrados e na fundamentação teórica, sempre buscando dar sentido ao que se escondia sob a realidade aparente, isto é, interpretar verdadeiramente os discursos enunciados e agregar-lhes valor.

Esta pesquisa procurou atender aos passos recomendados pelo protocolo de qualidade de estudos qualitativos Consolidated Criteria for Reporting Qualitative Research (COREQ). Este protocolo é um guia de pesquisa composto por 32 itens considerados necessários para a realização de pesquisa qualitativa ${ }^{(11)}$ e segue os pressupostos éticos da Resolução no 466/12 do Conselho Nacional de Saúde ${ }^{(12)}$. Além disso, foi aprovada pelo Comitê de Ética em Pesquisa (CEP) da Universidade Federal de Sergipe, sob o Parecer $n^{\circ}$ 4.330.332 e CAEE 30710920.1.0000.5546.

\section{Resultados}

Participaram do estudo 11 enfermeiros, dentre os quais, 8 do sexo feminino e 3 do sexo masculino, faixa etária média de 38 anos, com uma média de experiência na área de enfermagem de 15 anos e média de 5 anos na área de UTI.

Da análise das entrevistas emergiram categorias relacionadas ao tema do estudo que foram: Processo de trabalho do enfermeiro nas Unidades de Terapia Intensiva, Fatores que interferem na satisfação profissional do enfermeiro no âmbito da UTI e Relação do enfermeiro com a satisfação profissional no ambiente de terapia intensiva durante a pandemia Covid-19.

\section{Processo de trabalbo do enfermeiro nas Unidades de Terapia Intensiva}

Os discursos desta categoria demonstram que os enfermeiros consideram a autonomia um aspecto importante no seu processo de trabalho e de suma importância para a concretização da prestação de uma assistência de qualidade ao paciente grave. Mediante a SAE e a operacionalização do processo de enfermagem, o enfermeiro reforça sua capacidade de exercer sua profissão 
com autonomia e promover um cuidado individualizado e seguro, de acordo com as necessidades específicas de cada paciente.

Sim, mas autonomia se deve ao fato de você conquistar, ela não é lhe dada, e sim, conquistada. A partir do momento que você estuda, demonstra segurança no que está fazendo, você consegue ter uma autonomia com a equipe de enfermagem e demais profissionais. (I5).

Acredito que sim, porque a gente tá mais próximo do paciente e tem uma equipe integrada. A própria rotina da UTI permite que você trabalhe mais de perto com os técnicos, permite que o processo de trabalho e a SAE sejam mais objetivos. Até porque prestar assistência ao paciente crítico requer um olhar minucioso já que ele depende de nós para tudo. (I8).

Ao serem indagados sobre o aporte tecnológico utilizado na UTI, afirmaram que este contribui para que o enfermeiro preste uma assistência segura ao paciente crítico. Entretanto, esse profissional precisa estar capacitado para associar seus conhecimentos científicos ao uso da tecnologia e das necessidades assistenciais do paciente, como demonstrado nas respostas a seguir:

\begin{abstract}
A tecnologia é uma ferramenta para auxiliar na assistência, mas quem vai traduzir os dados que ela dá é o enfermeiro, então, ele precisa ser capacitado, qualificado para tal tarefa. É preciso também associar a clí nica do paciente com a fisiologia e patologia e não só levar em consideração os dados que o aporte tecnológico me diz. (I3).
\end{abstract}

Em partes, porque o aporte tecnológico por si só não vai te dar segurança na assistência se você não souber interpretar e manusear o que está vendo. (I5).

A respeito da assistência prestada aos pacientes dessa UTI, quando questionados se esta era satisfatória, os participantes afirmaram que sim, que conseguem sentir satisfação com o cuidado que ofertam aos seus pacientes, mas acreditam que poderia ser melhor se alguns fatores presentes no dia a dia fossem solucionados, conforme pode ser percebido nos depoimentos:

Das UTIs que trabalhei até hoje, sendo hospital particular ou público, a daqui pode ser considerada uma das melhores. Lógico que sempre se pode melhorar algo, mas nesta, temos uma boa equipe de técnicos, enfermeiros bem comprometidos, então estou muito satisfeita com a assistência que presto aos meus pacientes. (I5)

Enquanto enfermeiro de UTI, acho a assistência daqui satisfatória tanto para o paciente quanto pra mim. A equipe multiprofissional como um todo tem uma boa capacitação, então isso é satisfatório. Porém, os recursos tecnológicos poderiam melhorar, como, por exemplo, ter uma farmácia satélite e ter o suporte da engenharia clínica nos periodos noturnos, finais de semana $e$ feriado, porque quando não temos esse suporte acaba sendo responsabilidade do enfermeiro resolver os problemas que surgem. (I9).

\section{Fatores que interferem na satisfação profissional do enfermeiro no ambiente da UTI}

Nesta categoria, os entrevistados consideraram que para exercerem suas atividades laborais alguns fatores interferem na sua satisfação profissional. Dessa forma, surgiram as seguintes subcategorias:

\section{Remuneração}

Os relatos desta subcategoria revelam que os enfermeiros consideram a remuneração um ponto positivo nesse hospital, uma vez que o salário é alto quando comparado a outras instituições de saúde. Entretanto, ressaltam que é importante levar em consideração não apenas a remuneração, mas também as condições que o ambiente de trabalho oferta ao profissional. A satisfação profissional nem sempre é sobre remunera-
ção. Aqui a remuneração é boa, mas você pode estar sa-
tisfeito ganhando menos às vezes, tudo depende do seu
ambiente de trabalho, das condiçôes de trabalho que te
proporcionam. (19).

A remuneração aqui seria um ponto positivo, mas acredito que não é o mais importante. Porque também depende de como você se sente em seu ambiente de trabalbo. (I11).

\section{Carga horária de trabalho}

As falas evidenciam uma insatisfação profissional com a carga horária de 36h semanais estabelecida pela instituição e ressaltam a importância da regulamentação para 30h semanais para a categoria de enfermagem:

A carga borária de trabalbo como um todo influencia na satisfação profissional. E aí, nos remete a velha luta pela carga horária das $30 \mathrm{~h}$ semanais, porque acho que na UTI o enfermeiro é muito consumido, solicitado. (I2).

A enfermagem é muito sobrecarregada neste setor e isso de certa forma gera um pouco de insatisfação no profissional. Por isso, acho excessiva as $36 \mathrm{~h}$ semanais daqui principalmente se tratando do enfermeiro intensivista que exerce um trabalho complexo. O ideal mesmo seria a regulamentação das 30 bemanais para a enfermagem. (IO).

Quando mais exausto você tá psicologicamente e fisicamente, isso vai interferir na assistência prestada. Uma vez que, a carga de trabalbo exaustiva interfere na sua atenção, no risco de cometer iatrogenias. (I9). 


\section{Trabalho em equipe}

Em relação a esta subcategoria, os enfermeiros consideraram o trabalho em equipe um fator relevante para a satisfação profissional e enfatizaram a existência da visita multiprofissional, como meio de ofertar uma assistência segura, eficaz e de qualidade.

Na UTI há uma discussão sobre os pacientes de forma multi e possibilita que a equipe fique mais integrada em termos de comunicação e de objetivos estabelecidos para cada paciente. (I3).

A visita multiprofissional diária possibilita que os colegas médicos percebam o quanto os enfermeiros, fisioterapeutas, nutricionistas e as outras categorias profissionais estão presentes na assistência e a importância destes no cuidado e no tratamento. E, que sem essas categorias ele não consegue atuar de forma completa no tratamento do paciente. (I7).

\section{Relação do enfermeiro com a satisfação profissional no ambiente de terapia intensiva durante a pandemia Covid-19}

De acordo com os enfermeiros que atuaram na UTI Covid (durante o período em que este setor estava funcionando), essa experiência foi motivo de satisfação em sua vida profissional, apesar da exaustão e do desafio de prestar assistência a pacientes críticos que possuíam uma patologia tão desconhecida:

\begin{abstract}
Atuando como enfermeira intensivista na UTI Covid tive um misto de emoções. Tive momentos de sair muito insatisfeita por ver tantos pacientes indo a óbito, mas, em contrapartida, vi muitos ficarem grave e conseguirem sair bem da UTI e isso traz uma satisfação imensa. Porque você vê que todo seu esforço, dedicação e trabalbo resultou na recuperação do paciente mesmo diante dos impasses como ter uma equipe heterogênea onde a maior parte não tinha experiência em trabalhar com paciente crítico. (I4).

Tive a oportunidade de atuar na UTI Covid desde a admissão do primeiro paciente e costumo dizer que foi uma experiência ímpar. Acho que nos esforçamos ao máximo para tentar ofertar uma assistência de qualidade, fiquei satisfeita pelo tanto que fizemos, apesar de sair esgotada porque o plantão era muito pesado. Mas foi uma experiência fenomenal, me satisfez enquanto pessoa e profissional. (I7).
\end{abstract}

Não obstante, esta categoria identificou diferentes visões por parte dos enfermeiros que permaneceram na UTI geral do referido hospital. Estes relataram que se sentiram insatisfeitos porque não obtiveram o devido cuidado por parte da gestão para com a sua atuação nesse período tão caótico e, consequentemente, sentiram-se mais vulneráveis aos riscos inerentes à sua prática profissional durante uma pandemia, conforme evidenciado nas falas a seguir:

\begin{abstract}
Talvez se o bospital tivesse ofertado um treinamento bomogêneo para todas as equipes assistenciais e não só para os setores Covid, muita coisa poderia ter sido evitada. Aqui na UTI geral, só iniciaram os treinamentos quando surgiram os primeiros casos de Covid no setor e depois de ter sido feita uma solicitação formal foi que os EPIs passaram a ser mais completos. Isso gerou uma insatisfação na equipe. (I9).

Por se tratar de um momento tão delicado na área da saúde, confesso que como profissional me senti bastante insatisfeito pela forma como a gestão do hospital conduziu as coisas. Acho que deveriam ter criado fluxos mais criteriosos pra admissão de pacientes, já que montaram uma UTI especifica para atender paciente com Covid. Deveriam ter tido uma preocupação maior com a equipe da UTI geral através da oferta de capacitações antes mesmo dos primeiros casos serem confirmados. (I6).
\end{abstract}

\section{Discussão}

Com o decorrer dos anos, a enfermagem evoluiu enquanto ciência e profissão, deixando de ser desenvolvida pela visão estigmatizada de cuidados generalizados sem embasamento teórico e subsidiado pelo conhecimento médico, para hoje ser embasada no conhecimento científico por meio da SAE, operacionalizada pelo Processo de Enfermagem e guiada por legislação própria, como normatiza o Conselho Federal de Enfermagem (COFEN). Após a aplicação da assistência de enfermagem sistematizada, o enfermeiro pode alcançar sua autonomia profissional, devendo, portanto, ser a essência de sua prática ${ }^{(13)}$.

Dessa forma, compreende-se que, quando o enfermeiro possui autonomia em seu ambiente de trabalho, ele tem o controle sobre as suas decisões profissionais e mais independência em suas ações. Esse aspecto reforça a importância do enfermeiro tomar decisões clínicas baseadas nos saberes técnico-científicos, no pensamento crítico e nas legislações que respaldam o exercício da sua profissão ${ }^{(14)}$.

No que tange às resoluções estabelecidas pelo COFEN, a no 358/2009 contribui para fortalecer a autonomia do profissional enfermeiro. Esta resolução dispõe sobre a SAE e a 
implementação do Processo de Enfermagem em todo local público ou privado em que ocorre o cuidado de enfermagem $^{(14)}$. Assim, como evidenciado nos discursos dos entrevistados, a SAE e o Processo de Enfermagem são considerados ferramentas fundamentais na UTI, pois permite ao enfermeiro atuar com autonomia, empregando seus conhecimentos técnico-científicos de forma sistematizada e individualizada, para que, dessa forma, possa contribuir com o restabelecimento clínico e funcional do paciente.

Além disso, estudos sinalizam que a Unidade de Terapia Intensiva é também um ambiente complexo do setor hospitalar, caracterizado pela alta tecnologia para o cuidado ao paciente crítico e que exige do enfermeiro conhecimento para identificação e intervenção nas alterações fisiológicas dos pacientes, exercendo elevada capacidade de organização e competência clínica para o atendimento das diversas demandas da unidade e do paciente ${ }^{(3)}$.

Nesse sentido, os participantes do estudo corroboram esta ideia ao citarem que possuir um bom aporte tecnológico no ambiente de terapia intensiva, configura-se como uma ferramenta importante para prestação da assistência ao paciente crítico. Entretanto, ressaltaram a necessidade do enfermeiro possuir elevado nível de conhecimento técnico e científico para utilizar a tecnologia de forma adequada, possibilitando a realização de procedimentos invasivos inerentes à sua competência de forma segura e contribuindo para a monitorização contínua de seus pacientes.

Diante desse contexto, no âmbito da terapia intensiva, o trabalho do enfermeiro inclui lidar diariamente com o duelo entre a vida e a morte, o aspecto tecnológico e o aspecto humano do cuidado, bem como utilizar seus conhecimentos exercendo o senso crítico e ético em cada procedimento executado, visando a prestação de cuidado eficaz e a segurança do paciente ${ }^{(3)}$.

Ressalta-se, ainda, que ao enfermeiro intensivista compete assistir o indivíduo nas diferentes situações críticas dentro da UTI, de forma integrada e contínua com os membros da equipe de saúde. Vale lembrar que o processo de trabalho do enfermeiro de UTI possui a dimensão assistencial e gerencial, em que ambas devem se complementar, pois estão relacionadas ao tipo de assistência ofertada ${ }^{(15)}$.

A respeito do exposto, os enfermeiros relataram que se sentem satisfeitos com o cuidado que ofertam aos seus pacientes, pois trabalham com profissionais capacitados, seja do nível técnico ou superior. Entretanto, acreditam que essa assistência poderia ser melhor se aspectos gerenciais da rotina da UTI fossem solucionados. Relataram, por exemplo, a não existência do suporte da engenharia clínica em horários específicos. Dessa forma, caso surja uma demanda, torna-se responsabilidade do enfermeiro resolver, para não comprometer a assistência prestada, o que, consequentemente, resulta em mais uma tarefa em meio a tantas outras que são inerentes à sua profissão.

Dessa forma, quando fazemos referência às atividades desenvolvidas pelos enfermeiros de uma UTI, é importante lembrar que apesar desses profissionais serem responsáveis diretamente na prestação da assistência ao paciente, em muitos momentos, existe uma sobrecarga das atividades gerenciais em detrimento das atividades assistenciais. Questão que merece atenção, para que este profissional não se sinta sobrecarregado tentando solucionar problemas do setor ou de outros profissionais, visando atender demandas emergentes, e possa dedicar seu tempo laboral ao planejamento e implementação do cuidado qualificado e seguro ao paciente ${ }^{(15)}$.

Ademais, para exercer uma atividade laboral, o profissional usa aspectos intrínsecos e extrínsecos. Os fatores intrínsecos estão relacionados à forma positiva como ele percebe o seu trabalho por meio de seu autorreconhecimento, autonomia e realização profissional. Os fatores extrínsecos referem-se a aspectos do trabalho, como supervisão, remuneração, relacionamento interpessoal, condições de trabalho e qualidade da gestão ${ }^{(16)}$.

Logo, compreende-se que a satisfação no trabalho está diretamente interligada a componentes que contribuem para o desenvolvimento pessoal, reconhecimento e autorrealização, os 
quais estão relacionados aos resultados obtidos frente às experiências vivenciadas e à responsabilidade inerente ao cargo ocupado ${ }^{(1)}$.

Nessa perspectiva, o estudo evidenciou que a remuneração, carga horária de trabalho e trabalho em equipe são considerados fatores influenciadores na satisfação profissional, segundo a fala dos enfermeiros. No tocante à remuneração, chamaram atenção para o fato da remuneração por si só não ser garantia da satisfação do profissional, afirmando que é importante levar em consideração as condições que o ambiente de trabalho oferta ao profissional.

Esses depoimentos corroboram o fato de que o profissional que gosta do que faz no seu local laboral, desenvolve suas atividades de forma prazerosa e primorosa; mas, para isso, é necessário que a instituição de saúde proporcione ao trabalhador recursos humanos, físicos e materiais necessários a fim de prestar uma assistência eficaz e eficiente. A ausência desses recursos dificulta o desenvolvimento das práticas em saúde e poderá desencadear uma redução na qualidade da assistência, e, consequentemente, colocar em risco a saúde do paciente ${ }^{(1)}$.

No que se refere à carga horária de trabalho, percebeu-se insatisfação com a escala de $36 \mathrm{~h}$ semanais estabelecida pelo hospital. Os enfermeiros ressaltaram a importância da regulamentação das 30h semanais para a categoria de enfermagem, principalmente para o enfermeiro de UTI, que desenvolve uma prática complexa da assistência lidando com pacientes hemodinamicamente instáveis e que requerem total dependência dos cuidados de Enfermagem.

Um estudo realizado em 2016 afirmou que uma carga horária de trabalho excessiva contribui para o adoecimento físico e psíquico do trabalhador. Fato que contribui para o absenteísmo, estresse ocupacional, acidentes de trabalho, iatrogenias, exaustão, sobrecarga laboral e ausência de lazer ${ }^{(17)}$.

Dessa forma, compreende-se a importância de ofertar uma carga de trabalho não exaustiva ao profissional, pois quando ele está satisfeito com seu ambiente de trabalho e as atividades exercidas, irá desempenhar um cuidado integral aos seus pacientes, possibilitando uma assistência segura e eficaz. Portanto, dar atenção à saúde do trabalhador significa investir na qualidade da assistência ${ }^{(16)}$.

Em relação ao trabalho em equipe, os depoimentos demonstraram que os entrevistados consideram importante o trabalho em equipe na satisfação profissional, percebendo-o como uma forma de integrar a equipe multiprofissional da UTI e ofertar um cuidado mais completo ao paciente. Ressaltam também que a existência da visita multiprofissional diária à beira do leito que acontece na UTI, é uma oportunidade de discussão de forma conjunta sobre a evolução clínica dos pacientes, prescrições, futuras intervenções e programação de alta.

Tal achado encontra respaldo na literatura atual, quando esta afirma que a articulação do trabalho em equipe multiprofissional apresenta-se como aspecto fundamental para a satisfação profissional e para um cuidado que deve ser norteado no pensamento de que o paciente e suas necessidades de saúde, eventualmente, depende de todos os profissionais, com igual intensidade, dentro da área de competência de cada $\mathrm{um}^{(4)}$.

Outro ponto que se relaciona com a satisfação profissional é a valorização da categoria Enfermagem. Diante dessa percepção, em 2020, houve a comemoração do bicentenário de Florence Nightingale, e a OMS e o Conselho Internacional de Enfermeiros criaram a campanha mundial Nursing Now, que visou chamar a atenção dos países integrantes da Organização Mundial das Nações Unidas (ONU) para a importância de valorizar o trabalho da Enfermagem ${ }^{(13)}$.

No decorrer da Campanha Nursing Now o mundo foi surpreendido com o surgimento de uma doença desconhecida, ocasionada pelo vírus SARS-CoV-2, declarada como pandemia Covid-19 pela OMS em março de 2020, que, consequentemente, tornou-se um grave problema de saúde pública. No mesmo mês, o Ministério da Saúde (MS) reconheceu a doença como transmissão comunitária em todo território nacional. Diante disso, o MS e todas as esferas de governo depararam-se com a necessidade de criar 
estratégias para reestruturar os estabelecimentos de saúde e suas equipes para combater o vírus e minimizar a elevação dos casos, buscando evitar o colapso na saúde pública brasileira ${ }^{(18)}$.

A respeito do cenário da pandemia, os profissionais entrevistados relataram que, no hospital em que trabalham, foi estruturada uma UTI específica para atender os pacientes com Covid-19, a qual contava com 14 leitos. Os enfermeiros que atuaram nessa UTI expressaram que, apesar de ser extremamente desafiador prestar assistência a um paciente crítico que possuía uma patologia tão difícil e ainda desconhecida em muitos aspectos pela comunidade científica, a experiência foi algo gratificante no sentido de poder contribuir na recuperação do paciente.

Esses depoimentos evidenciam o quanto a enfermagem é essencial nos serviços de saúde, além de ser a maior categoria profissional de saúde com milhares de enfermeiros em todo o mundo. Os enfermeiros seguem prestando assistência à população no contexto da pandemia, desde a triagem de casos suspeitos até a prestação de cuidados hospitalares nos pacientes internados que desenvolvem complicações graves da doença. Assim, o trabalho desses profissionais é fundamental para o enfrentamento da pandemia $^{(19)}$.

Ademais, o enfermeiro atuante na linha de frente de combate ao Covid-19 conta com o respaldo legal que regulamenta a sua profissão. Mesmo diante das dificuldades impostas por uma pandemia (como o risco de se contaminar e contaminar seus familiares, as longas jornadas de plantões, o nível de extrema complexidade de seus pacientes, entre outras), exercem sua profissão utilizando sua autonomia nas atividades executadas, com dedicação e buscam superar os desafios que surgem ao longo da jornada assistencial juntamente com a sua equipe multiprofissional, visando alcançar uma boa prestação da assistência e sua autorrealização enquanto enfermeiro ${ }^{(20)}$.

Por outro lado, os enfermeiros participantes deste estudo que permaneceram na UTI geral revelaram um sentimento de insatisfação por não terem sido vistos com o mesmo olhar de importância e preocupação pela gestão do hospital. Relataram que os treinamentos não foram prioridade naquele setor no início da pandemia, que só passaram a acontecer depois dos primeiros casos confirmados, e que a disponibilidade de equipamentos de proteção individual era um fator de extrema dificuldade.

Nesse sentido, a literatura ressalta o quanto é relevante ter um suporte organizacional e o aperfeiçoamento das práticas assistenciais, fatores do ambiente que envolvem a organização do trabalho e meios para o alcance de melhores resultados na prestação da assistência. Essas características tornam-se essenciais para a satisfação profissional, pois possibilita desenvolver o gerenciamento para as boas práticas do cuidado e, consequentemente, profissionais capacitados capazes de ofertar um cuidado seguro para si e seus pacientes, seja nas interfaces vivenciadas na rotina diária da área da saúde, seja em tempos de pandemia ${ }^{(21)}$.

Por fim, destaca-se como limitação do presente estudo o fato de ter sido realizado em apenas um hospital público do estado de Sergipe. Dessa forma, percebe-se a necessidade da realização de mais estudos em outros hospitais e cenários, sejam eles públicos ou privados, para vivenciar diferentes realidades, a fim de expandir as concepções dos participantes acerca do tema abordado, visando enriquecer os resultados obtidos. Ademais, como contribuição, o estudo possibilitou uma melhor reflexão do enfermeiro de UTI sobre a importância da satisfação profissional acerca do ambiente de trabalho escolhido e os benefícios que isso pode acarretar no desenvolvimento de suas atividades perante a prestação da assistência ao paciente crítico.

\section{Considerações finais}

Este estudo possibilitou compreender que os enfermeiros da UTI consideram a satisfação profissional um aspecto importante no seu ambiente de trabalho e reconhecem que ela pode influenciar na prestação da assistência ofertada aos pacientes. 
Assim, os enfermeiros perceberam que a satisfação profissional não se trata de algo isolado, pelo contrário, está diretamente associada a fatores presentes no dia a dia do seu exercício laboral, como autonomia, remuneração digna, carga horária de trabalho excessiva e trabalho em equipe. Isso evidencia que o meio laboral no qual o profissional está inserido e as condições que o ambiente oferta influenciam diretamente na sua satisfação e qualidade do cuidado prestado.

Por isso, é imprescindível que as instituições de saúde possuam um suporte organizacional que vise o aprimoramento do cuidado ofertado, no qual o profissional além de ser visto como provedor de cuidados de saúde, seja visto também como um sujeito que precisa estar inserido em um ambiente de trabalho que o valorize enquanto enfermeiro e ofereça recursos físicos, materiais e humanos que contribuam para a efetivação de uma assistência holística e integral ao paciente em cuidados intensivos.

\section{Colaborações:}

1 - concepção, projeto, análise e interpretação dos dados: Cícera Eugênia Pereira da Silva e Janine Melo de Oliveira;

2 - redação do artigo e revisão crítica relevante do conteúdo intelectual: Emilenny Lessa dos Santos e Viviane Farias Barros;

3 - aprovação final da versão a ser publicada: Emilenny Lessa dos Santos, Cyndi Myrelle da Silva Barros Romão, Josefa Jadiane dos Santos e Mariana Barbosa da Silva.

\section{Referências}

1. Ozanam MAQ, Santos SVM, Silva LA, Dalri RCMB, Bardaquim VA, Robazzi MLCC. Satisfação e insatisfação no trabalho dos profissionais de enfermagem. Braz J of Develop. 2019;5(6):6156-8. DOI: https://doi.org/10.34117/ bjdv5n6-127

2. Morais BX, Pedro CMP, Dalmolin GL, Silva MA. Satisfação profissional de trabalhadores de enfermagem de um serviço de hemato-oncologia. Rev Rene. 2018;19:e3165. DOI: $10.15253 / 2175-6783.2018193165$

3. Ouchi JD, Lupo APR, Alves BO, Andrade RV, Fogaça MB. O papel do enfermeiro na unidade de terapia intensiva diante de novas tecnologias em saúde. Saúde Foco [Internet]. 2018 [cited 2019 Jul 14];(10):412-28. Available from: https:// portal.unisepe.com.br/unifia/wp-content/ uploads/sites/10001/2018/07/054_O_PAPEL_DO_ ENFERMEIRO_NA_UNIDADE_DE_TERAPIA_ INTENSIVA.pdf

4. Silva MFL, Alves ESRC, Santos EM. Desafio ao enfermeiro nas ações assistenciais e gerenciais na unidade de terapia intensiva. Temas em Saúde [Internet]. 2019 [cited 2020 Nov 22]; 19(4):116-32. Available from: http://temasemsaude.com/wpcontent/uploads/2019/09/19408.pdf

5. Conselho Federal de Enfermagem. Lei do Exercício Profissional de Enfermagem no 7.498, de 25 de junho de 1986 [Internet]. Brasília (DF); 1986 [cited 2021 Apr 3]. Available from: http://www.cofen. gov.br/lei-n-749886-de-25-de-junho-de-1986_4161. html

6. Viana RAPP, Torre M, editoras. Enfermagem em Terapia Intensiva: práticas integrativas. Barueri (SP): Manole; 2017.

7. Souza LPS, Souza AG. Enfermagem brasileira na linha de frente contra o novo Coronavírus: quem cuidará de quem cuida? J Nurs Health. 2020;10(4):e20104005. DOI: HTTPS://DOI. ORG/10.15210/JONAH.V10I4.18444

8. Oliveira AC. Challenges faced by nursing professionals in the Covid 19 pandemic. REME rev min enferm. 2020;24:e-1302. DOI: $10.5935 / 1415-2762.20200032$

9. Paulino GME, Matta ACB, Camilo NRS, Simões AC, Nishiyama JAP, Oliveira JLC, et al. Professional satisfaction and work environment of the nursing team in intensive care units. REME rev min enferm. 2019;23:e1271. DOI: $10.5935 / 1415-2762.20190119$

10. Bardin L. Análise de conteúdo. Lisboa: Edições 70; 2016.

11. Allison T, Peter S, Jonathan C. Critérios consolidados para relatar pesquisas qualitativas (COREQ): uma lista de verificação de 32 itens para entrevistas e grupos de foco. Int $\mathrm{J}$ Qual Health Care. 2007;19;349-57. DOI: https://doi. org/10.1093/intqhe/mzm042 
12. Brasil. Ministério da Saúde. Conselho Nacional de Saúde. Resolução no 466, de 12 de dezembro de 2012. Diretrizes e normas regulamentadoras da pesquisa envolvendo seres humanos [Internet]. Brasília (DF); 2012 [cited 2019 Jul 14]. Available from: http://bvsms.saude.gov.br/bvs/saudelegis/ cns/2013/res0466_12_12_2012.html

13. Raposo AC, Santos KCB, Gonçalves MMC, Coimbra LLM, Dias RS. A satisfação profissional do enfermeiro assistencial em um hospital de ensino. Temas em Saúde [Internet]. 2020 [cited 2020 Nov 8];20(1):360-89. Available from: http://temasemsaude.com/wp-content/ uploads/2020/02/20121.pdf

14. Dutra S. Autonomia do enfermeiro em terapia intensiva no cuidado ao paciente queimado [trabalho de conclusão de curso]. Florianópolis (SC): Universidade Federal de Santa Catarina; 2019.

15. Vargas D, Braga AL. O Enfermeiro de Unidade de Tratamento Intensivo: Refletindo sobre seu Papel. Revista Online. [cited 2021 Abril 4]. Available from: https://www.unifafibe.com.br/ revistasonline/arquivos/revistafafibeonline/ sumario/10/19042010093459.pdf

16. Vieira GC, Ribeiro KV, Velasco AR, Pereira EAA, Cortez EA, Passos JP. Satisfação laboral e a repercussão na qualidade de vida do profissional de enfermagem. ABCS Health Sci. 2018;43(3):186-92. DOI: http://dx.doi.org/10.7322/ abcshs.v43i3.1123
17. Morais MP, Martins JT, Galdino MGQ, Robazzi MLCC, Trevisan GS. Satisfação no trabalho de enfermeiros em um hospital universitário. Rev enferm UFSM. 2016;6(1):1-9. DOI: $10.5902 / 2179769217766$

18. Bitencourt JVOV, Meschial WC, Frizon G, Biffi P, Souza GB, Maestri E. Nurse's protagonism in structuring and managing a specific unit for Covid-19. Texto contexto - enferm. 2020;29:e20200213. DOI: https://doi.org/10.1590/ 1980-265X-TCE-2020-0213

19. Oliveira EM, Barbosa RL, Andolhe R, Eiras FRC, Padilha KG. Nursing practice environment and work satisfaction in critical units. Rev Bras Enferm. 2017;70(1):79-86. DOI: http://dx.doi. org/10.1590/0034-7167-2016-0211

20. Brito LL, Simonvil S, Giotto AC. Autonomia do profissional de enfermagem diante da covid-19: revisão integrativa. Rev Inic Cient Ext. 2020 [cited 2021 Abril 4];3(2):420-37. Available from: https://revistasfacesa.senaaires.com.br/index.php/ iniciacao-cientifica/article/view/300/242

21. Oliveira KKD, Freitas RJM, Araújo JL, Gomes JGN. Nursing Now e o papel da enfermagem no contexto da pandemia e do trabalho atual. Rev Gaúcha Enferm. 2021;42(esp):e20200120. DOI: https://doi.org/10. 1590/1983-1447.2021.20200120

Recebido: 18 de dezembro de 2020

Aprovado: 10 de maio de 2021

Publicado: 31 de maio de 2021

A Revista Baiana de Enfermagem utiliza a Licença Creative Commons - Atribuição-NãoComercial 4.0 Internacional. https://creativecommons.org/licenses/by-nc/4.0/

Este artigo é de acesso aberto distribuído sob os termos da Licença Creative Commons (CC BY-NC). Esta licença permite que outros remixem, adaptem e criem a partir do seu trabalho para fins não comerciais. Embora os novos trabalhos tenham de lhe atribuir o devido crédito e não possam ser usados para fins comerciais, os usuários não têm de licenciar esses trabalhos derivados sob os mesmos termos. 